\title{
APRENDIBILIDAD- ENSEÑABILIDAD- EDUCABILIDAD: UNA DISCUSIÓN
}

\author{
Rómulo Gallego Badillo \\ y Royman Pérez Miranda*
}

\section{Introducción}

Las interacciones entre aprendibilidad, enseñabilidad, educabilidad, aprender, enseñar y educarse, configuran un campo nuevo de investigación que le da a los saberes pedagógicos y didácticos una dimensión diferente a la que hasta ahora se le había venido atribuyendo. Es todo un reto de teorización que exige la inscripción en replanteamientos conceptuales y metodológicos en relación, por lo menos, con enseñar, aprender y educar; una revisión crítica de los presupuestos epístemológicos que subyacen tales conceptos.

Se piensa que, desde la perspectiva anotada, lo pedagógico y lo didáctico dejan de ser instancias mediadoras, propias de miradas instrumentalistas que han impedido un desarrollo, relativamente autónomo, de dichos saberes. En este ensayo, en consecuencia, se persigue elaborar un punto de vista distinto, centrado en el análisis de la aprendibilidad, la enseñabilidad y la educabilidad.

\section{Sobre el aprender}

El aprender o el aprendizaje ha de examinarse como un concepto propio de las teorías pedagógicas y didácticas. Como conceptualización hay que atribuirle unos presupuestos ontológicos y epistemológicos desde los cuales adquiere su fundamentación y su aceptabilidad en el interior de la comunidad de especialistas que se ocupa de construir, contrastar y sustentar propuestas paradigmáticas en este campo de indagación y práctica académicas.

En principio, como conceptualización, hay que afirmar que posee una historia interna y externa (Lakatos, I., 1983); la externa, influenciada por los contextos culturales, sociales, políticos y económicos, que han hecho de cada concepto de aprender o de aprendizaje el requerido para cada proyecto de sociedad. Así, y para los propósitos del presente ensayo, se presentan aquí el llamado aprendizaje mecanicista y el aprendizaje como construcción.

\section{Aprendizaje mecanicista}

Como recepción verbal de información que ha de ser memorizada y repetida al pie de la letra es el concepto propio de la educación tradicional. Es el mismo que se halla en la base de la psicología behaviorista y su corriente del conductismo operante (Skinner B .F.,19 86), basado en la relación E-O-R, que fundamentó los programas instruccionales, desde sus compromisos epistemológicos de carácter empiropositivista.

Hay que entenderlo. El sujeto que aprende, para esta concepción, lo hace siempre de una misma manera; sigue, si se quiere, un mismo procedimiento, una metódica fija. De esta forma, ese sujeto en cuanto aprendiz ha de ser permanentemente lo que es; no puede cambiar, ya que dejaría de ser. Aprender es acumular, llenar un vacío, un ir de una

\footnotetext{
* Profesores Universidad Pedagógica Nacional.
} 
ignorancia (carencia) a un saber (tenencia); un proceso lineal que obedece a la relación de proporcionalidad (cantidad de información transmitida versus cantidad de información retenida) de la ley de causa (enseñar)- efecto (aprender).

En el interior de este reduccionismo, parecería no ser necesario discutir el problema de la aprendibilidad, ya que todo lo que podría decirse al respecto, se halla ya precisado, por lo que los esfuerzos habría que dirigirlos a mejorar la eficiencia (tecnología educativa) de los procesos de transmisión y captura de información (tecnologías de la información).

\section{Aprendizaje como construcción}

Por otro lado, las concepciones no mecanicistas del aprendizaje se inician con la "epistemología genética" de Jean Piaget y con la propuesta de David Ausubel.

El primero, plantea el aprendizaje como asimilación y desasimilación, en el contexto de equilibraciones y desequilibraciones del sujeto que aprende, en relación con su entorno. Para Piaget existen unas estructuras mentales que ese sujeto construye. El segundo, propone como alternativa al aprendizaje memorístico el significativo, en términos de acomodaciones de lo que se aprende a las estructuras conceptuales preexistentes en el aprendiz (Ausubel, D., Novak, J.D. y Henesian, H., 1983). Ese aprendizaje procede por construcción de significados. Los nuevos contenidos curriculares son interpretados previamente por el sujeto que aprende, desde su estructura conceptual; al incorporar eso nuevo y transformado en dicha estructura, la cambia a su vez (Moreira, M. A., 1990). El aprendizaje comienza así a manifestarse como un proceso complejo; el cual es evidenciable a través de la elaboración de mapas conceptuales (Novak, J.D. y Gowin, B., 1988).

Relacionada con los anteriores conceptos, se inicia una historia de conceptualizaciones progresivas constructivistas $y$, por tanto, deductivistas, a las que hay que clasificar como típicamente pedagógicas y didácticas, ya que en sus elaboraciones no han participado psicólogos y han resultado de las necesidades teóricas de los investigadores en la enseñanza y el aprendizaje de las ciencias. Hay suficientes argumentos teóricos para sostener que el ámbito de investigación que con ellos se delimita, no es un problema de la psicología, sino de los pedagogos y didactas.

Si bien con la tematización en lo conceptual se introduce el problema de lo epistemológico, es con la puntualización en la dialéctica entre lo conceptual y lo metodológico (lo conceptual es metodológico y éste a su vez conceptual, que los hace no separables), que entra a dominar lo epistemológico sobre lo psicológico, aun cuando éste se fortalece al incorporarse lo actitudinal. Con lo axiológico, se desbordan las limitaciones anteriores, para hacer del concepto de aprendizaje como cambio conceptual, metodológico, actitudinal y axiológico, un problema pedagógico y didáctico, en estricto sentido.

Los autores del presente ensayo creen que habría que pensar en un aprendizaje como cambio conceptual, metodológico, estético, actitudinal y axiológico, con miras a abandonar definitivamente las ataduras psicológicas. Es así, por cuanto desde los compromisos deductivistas-constructivistas, los saberes son estructuras teóricas coherentes $y$, en consecuencia, armónicas; de otra manera, se elaboran siguiendo relaciones de simetría entre sus partes. De cualquier forma, esa simetría o armonía es la que lleva a la atribución de belleza a las teorías. Lo estético de ellas se encuentra vinculado a lo afectivo de lo actitudinal. 
Destáquese que, en las concepciones constructivistas del aprendizaje, quien aprende no posee una mente vacía, ya que ella está siendo mediante estructuras conceptuales, metodológicas, estéticas, actitudinales y axiológicas. Lo actitudinal es actuacional y, por tanto, metodológico y conceptual. Es valorativo, es decir, axiológico, a la vez que volitivo, afectivo y transaccional, desde la perspectiva de que, en el fondo el problema es un juego de reconstrucción y construcción de nuevos significados, formas de significar y de actuar (Brunner, J., 1991). El convencimiento es el de que todos los saberes son elaboraciones colectivas que dependen de una historia cultural de producción, de conformidad con la tradición de comunidades de especialistas; las cuales se desenvuelven en los contextos de proyectos sociales, políticos y económicos tipificables, que valoran, estimulan y le asignan recursos a ciertos grupos y a determinadas investigaciones.

Obsérvese cómo en los conceptos constructivistas de aprendizaje hay una preocupación teórica por establecer una mirada humanística y compleja sobre el sujeto que aprende, buscando incorporarlo en toda su multidiversa dimensionalidad; es desde ahí que es introducible la teoría de complejidad y la de los sistemas dinámicos no lineales. Con mayor precisión, habría que sostener que el aprendizaje es una propiedad emergente y relacional, de tal manera que los procesos acerca de cómo se aprende, cambian y no siguen la relación de proporcionalidad simple de la ley causa-efecto. Es decir, el aprendizaje es una propiedad heraclítea. Es desde esta perspectiva que el planteamiento sobre la aprendibilidad precisa de un esfuerzo de teorización riguroso.

\section{La aprendibilidad}

Las concepciones deductivistas-constructivistas del aprendizaje ofrecen otra perspectiva desde dónde analizar el problema de la aprendibilidad. De entrada, habría que reiterar que quien aprende reconstruye y construye nuevos significados, formas de significar y de actuar intencionadamente; de esta manera, se halla en posicionamientos diferentes desde los cuales atribuir otros sentidos al mundo.

Puesto que los saberes circulan entre los miembros de las diferentes comunidades académicas de especialistas, a través de textos escritos (artículos, ensayos, libros didácticos, por ejemplo), toda aproximación a tales textos es realizada desde las estructuras conceptuales, metodológicas, estéticas, actitudinales y axiológicas que cada quien ha elaborado, y es desde ellas que hace las respectivas lecturas, atribuyéndoles el sentido que considera apropiado y pertinente. Puesto que por muy equivalentes que sean esas estructuras entre los miembros de la comunidad, no son estrictamente iguales unas a otras, es de esperarse que las lecturas no coincidan y, por tanto, que existan siempre controversias y la necesidad de negociar acuerdos programáticos.

Algo análogo ha de suponerse que sucede entre los aprendices. Interpretan los textos didácticos sobre los saberes académicos a partir de las estructuras señaladas independientemente de que esas interpretaciones sean o no las admisibles dentro de los miembros de la comunidad de especialistas. En la medida en que aprenden, en las perspectivas deductivístas-constructivistas, se aspira a que ellos cambien sus lecturas y modifiquen sus aproximaciones a los textos, atribuyéndoles sentidos diferentes de los iniciales. Dado que ese aprendizaje incide también sobre lo actitudinal, para subrayarlo, es de esperarse que modifiquen sus actitudes en relación con su condición de aprendices.

La aprendibilidad de un saber dado es así una atribución, una cualidad que le confiere cada alumno y cada alumna a ese saber. Puesto que el aprendizaje es intencional y está mediado por una actitud positiva, el alumno o la alumna le confieren al saber el sentido 
que ellos consideran contribuye mejor a su introducción en las formas como ese saber es trabajado por la respectiva comunidad de especialistas. Aprenden así lo que desean aprender o, de otra forma, aprenden los significados, las formas de significar y de actuar que reconstruyen y construyen, los cuales son en última instancia sus propias lecturas.

Construida la aprendibilidad por el alumno o la alumna, ésta canaliza los procesos de aprendizaje. La aprendibilidad determina el aprender, por cuanto refuerza la actitud positiva para que éste se inicie, en la medida en que prepara los esquemas actuacionales para enfrentar cognoscitivamente el texto. De otra manera, cada alumno o alumna ha de evaluar en qué forma el saber es aprendible por él o por ella y hasta dónde ha de llegar en dicha actividad. Tal presupuesto es el que hace del aprendizaje una actuación relacional, consciente y responsable, impulsándolos hasta alcanzar el llamado aprendizaje total, con su triple reconocimiento.

Una mirada elemental de la aprendibilidad puede, incluso, comenzar por el examen de las preguntas iniciales que podrían formularse los alumnos y las alumnas, en cuanto a sí el saber o la temática es aprendible por ellos y por ellas; de qué manera pueden aprenderlo o aprenderla; qué recursos cognoscitivos previos requieren; a quién o a quiénes deben acudir para que los o las ayude en ese cometido. Tales interrogantes presuponen, como se dijo, un sujeto activo: yo quiero aprender, como reconocimiento de que el saber o la temática en cuestión es necesario o necesaria para los respectivos proyectos éticos de vida.

El aprendizaje como cambio, que se desprende de la aprendibilidad elaborada, sólo tiene sentido para cada alumno y alumna, si el saber que va a aprender es significativo, de una manera demostrable, para el perfeccionamiento de sus proyectos éticos de vida. Es en el interior de esta expectativa existencial que ese aprendizaje es asumido como un compromiso de cada quien, en principio, impulsando el volver sobre la aprendibilidad, para las rectificaciones que el proceso demanda.

Puesto que en el proceso de aprendizaje cada alumno y cada alumna cambian sus estructuras, entonces, transforman sus lecturas modificando la atribución de sentido al saber objeto de aprendizaje. En consecuencia, la aprendibilidad que le confieren a ese objeto de aprendizaje se ve también afectada, hasta el punto de que la atribución inicial de aprendibilidad que han elaborado cambia; es decir, cada alumno y cada alumna vuelven al texto de una forma diferente, forma que hace que dicho texto, a pesar de ser el mismo, sea a la vez distinto. En otras palabras, en el proceso de aprendizaje la aprendibilidad nunca es la misma.

Hay aquí, como puede notarse, una relación dialéctica entre aprendibilidad y aprender. La primera determina al segundo, a la vez que el aprendizaje modifica la aprendibilidad, para reemprender la actividad en otro estadio cognoscitivo. Aprender no es acumular sino transformarse, cambiando la mirada sobre lo mismo; haciendo de aquello que se aprende objeto de saber e investigación, en la conciencia de que sobre aquello que es objeto de estudio, nada está dicho en definitiva. Téngase en cuenta, de acuerdo con lo afirmado, que ese volver a la aprendibilidad no es regresar al punto de partida, en estricto sentido, y seguir aprendiendo no es continuar en el mismo esquema metódico inicial.

Por otro lado, dado que todo saber es comunitario en la medida en que sus significados, formas de significar y de actuar sistemáticamente obedecen a negociaciones y acuerdos programáticos entre los miembros de cada comunidad académica de especialistas, al trasladar la situación al colectivo aula, bajo la orientación de un pedagogo 
y didacta, se tiene también que la aprendibilidad es una atribución colectiva, una propiedad del saber del que se trate, que emerge de las interacciones entre los miembros del colectivo aula con dicho saber. Se supone que el aprendizaje, por lo menos, tiene como horizonte de sentido la aproximación crítica a las interpretaciones y formas de actuar admitidas por la comunidad académica de especialistas.

Hay que dejar sentado el hecho de que, desde la perspectiva de la reconstrucción y construcción de nuevos significados, formas de significar y de actuar, el aprendizaje es una actividad que ha de realizar el sujeto cognoscente individual; es él quien tiene que comprometerse integralmente con dicha actividad. Es este el fundamento de la afirmación de que nadie aprende por otro. Puesto que se trata de significados, de que cada quien significa desde donde significa para los demás de su colectivo, las consecuencias de esa reconstrucción y construcción tienen que ser sometidas al juicio de los miembros del colectivo. Es aquí en donde la crítica realimenta esa reconstrucción y construcción, emergiendo la naturaleza comunitaria del aprendizaje: se aprende con los otros y en el seno de los otros.

La aprendibilidad, como atribución colectiva, aparece justamente en la confrontación que los miembros del colectivo aula hacen de sus propias interpretaciones; confrontaciones que han de posibilitar negociaciones y acuerdos programáticos en relación con el sentido, y para propósitos específicos, que han de darle a la aprendibilidad de un saber dado, en el tiempo y en el espacio en los que el proceso de aprendizaje se adelanta. Es claro que en dichas negociaciones y acuerdos realizan papeles preponderantes los intereses, las actitudes y los proyectos éticos de vida de cada uno de los integrantes del colectivo aula. De otra manera, las aprendibilidades individuales son modificadas por las negociaciones y acuerdos en cuanto que el aprendizaje posee la cualidad colectiva anotada.

En relación con los textos de los saberes, hay que decir que sus configuraciones estructurales inciden en las atribuciones individuales y comunitarias de aprendibilidad, en razón de que esos textos se ajustan a las respectivas lógicas disciplinares; lógicas que a su vez son construcciones históricas expresadas de conformidad con los compromisos epistemológicos de los autores. No resulta entonces descabellado pensar también, que los alumnos y las alumnas se aproximan a los textos desde posiciones que pueden ser interpretadas, igualmente, en términos de sus propios compromisos epistemológicos, sean estos ingenuos o elaborados rigurosamente, con sus propias razones culturales e históricas. Los aprendizajes han de desembocar en cambios dentro de dichos compromisos $\mathrm{y}$, por consiguiente, incidir en la aprendibilidad atribuida inicialmente.

Hacer alusión a los compromisos epistemológicos, desde los cuales se hacen las lecturas de los textos, por parte de alumnos y alumnas, es traer a cuento el hecho de que la construcción de la aprendibilidad por parte de ellos y ellas, requiere también de que elaboren una estructura disciplinar del saber del que se trate, no sólo en lo que el texto muestra, sino también en lo que le subyace.

Esa elaboración, por supuesto, estará sometida a cambios en la medida del mismo proceso de aprendizaje. Tal lectura de la estructura ha de mostrar cuáles son los otros saberes o disciplinas en los que se han apoyado conceptual y metodológicamente los autores y las razones que han tenido para allegar dicho apoyo. Así, la aprendibilidad elaborada genera el compromiso de aprender, en el nivel y profundidad requeridos, esos otros saberes a partir de los cuales se ha construido el saber objeto de aprendizaje. Este 
hecho, al mismo tiempo, despierta la necesidad de revisar críticamente la historia del saber objeto de aprendizaje.

No se puede pasar por alto. Cada lectura que realizan alumnos y alumnas del saber o temática objeto de aprendizaje, desde lo que ellos y ellas saben, y para efecto de elaborar la aprendibilidad, precisa de la construcción inicial de cuál es la estructura de ese saber o temática. La aprendibilidad ha de partir entonces de una atribución (atribución de atribución) al respecto. De otra manera, no podría entenderse cómo ellos y ellas podrían estar en condiciones de emprender sistemáticamente sus aprendizajes. Es claro que el emprendimiento del proceso revertirá necesariamente en una modificación de esa estructura inicial atribuida. Además, todas las estructuras asignadas individualmente son objeto de juicio en el colectivo.

Como puede notarse, una conceptualización del problema de la aprendibilidad parece ser mucho más compleja (sin agotarla) y admisible, desde una teoría de complejidad, en el seno de una ontología próxima a los presupuestos de Heráclito. Es una propiedad que emerge de interacciones diversas y múltiples. La historia de los diferentes saberes enseña cómo los cambios producidos en las miradas, han generado replanteamientos de diferentes órdenes en sus estructuras conceptuales y metodológicas.

\section{La enseñanza}

La actividad de enseñar es afectada por las concepciones de aprendizaje, de alumno y alumna, de profesor y profesora, por las intencionalidades curriculares y por los compromisos epistemológicos mismos de los profesores. De hecho, lo es también por la clase de formación profesional de que han sido objeto los profesores y profesoras, con el fin de asumir sus compromisos, ya sea como operarios o como trabajadores de los saberes en sus dimensiones y problemas epistemológicos, pedagógicos y didácticos.

En el contexto de los compromisos epistemológicos de naturaleza empiropositivista, que persiguen un aprendizaje memorístico y repetitivo, el enseñar se ve reducido a la transmisión de información adecuada a los niveles de comprensión de los discentes. Los saberes se didactizan simplificándolos para ponerlos al nivel de las estructuras de significados y de significaciones de los discentes; de esta manera, no son ellos quienes acceden, sino que son los docentes quienes se los entregan. Son así verdaderos intermediarios entre las comunidades académicas de especialistas y los discentes; en consecuencia, la pedagogía y la didáctica son meras instrumentaciones para dicha labor.

Por el contrario, en el interior de posiciones de carácter deductivistas-constructivistas, enseñar requiere de reconceptualizaciones apropiadas. Podría afirmarse que es crear ambientes epistemológicos, pedagógicos y didácticos que propicien experiencias de aprendizaje en la contextualización anotada. Tales ámbitos han de simular las comunidades académicas de especialistas; poner a disposición las informaciones requeridas, concitar discusiones, exigir contrastaciones rigurosas y convocar a negociaciones y acuerdos programáticos; todo sobre el presupuesto de la tolerancia y el respeto a las concepciones alternativas del otro.

\section{La enseñabilidad}

Antes de cualquier discusión sobre esta temática, hay que dejar sentado, de entrada, que la enseñabilidad tal cual como se va a problematizar le compete principalmente a profesores y profesoras que realizan su trabajo en el interior de su compromiso con un 
proyecto epistemológico, pedagógico y didáctico, de carácter investigativo, teóricamente fundamentado. Además de lo anotado en párrafos anteriores, es esta empresa la que los diferencia significativamente de los docentes operarios, centrados en la transmisión de información.

Aristóteles, en su Metafísica, informa cómo los griegos atribuían a la Episteme y a la Tekhné la categoría de saber, por cuanto eran experiencias compartibles con los demás, dado su carácter conceptual y público; no así la empiria, puesto que se trataba de una experiencia privada, no traducible en conceptos. Si ese compartir con los otros es también enseñar, podría sostenerse que desde Aristóteles la enseñabilidad es lo que hace que algo sea un saber. Si, en gracia de discusión, se parte de la idea de que Aristóteles comulgaba con la ontología de Parménides, entonces cabría concluir que el ser en sí y único de un saber se manifiesta en su enseñabilidad.

De ahí que, sólo existiría una manera de enseñarlo que dimanaría de su estructura, esto es, de su propia lógica disciplinar. En otras palabras, bastaría con el sólo dominio conceptual y metodológico de un saber dado para enseñar-lo, de tal manera que las elaboraciones pedagógicas y didácticas sobrarían o, a lo sumo, se restringirían a una cuestión meramente instrumental. Hay que anotar que esta posición, que podría tildarse de aristotélica, no tiene en cuenta que los saberes pedagógicos y didácticos propiamente dichos, inician su camino con la Modernidad; esa cultura que se instaura, dentro de las ciencias experimentales por lo menos, con una revisión radical de las posiciones teóricas de Aristóteles.

Por otro lado, la enseñabilidad puede ser planteada desde múltiples interrogantes: ¿es un saber en sí enseñable? ¿en qué medida es enseñable? ¿qué condiciones previas se requieren para pensar esas posibilidades de enseñabilidad? ¿a quién es enseñable? ¿para qué y por qué ha de enseñarse? ¿desde dónde se exige la enseñanza de ese saber? ¿qué se requiere para hacer factible la enseñanza? ¿es el sujeto a quien se le enseña un ente pasivo y meramente receptor de esa enseñanza? ¿Describe y explica el saber un conjunto de aconteceres, fenómenos y fenomenologías acerca de los cuales los alumnos y las alumnas han hecho elaboraciones, independientemente de que no sean las admitidas por las comunidades académicas de especialistas?

No se puede negar. En principio es aceptable que todos los saberes son estructuras conceptuales, metodológicas, estéticas, actitudinales y axiológicas, y que por tanto, son "leíbles", esto es, decodificables, interpretables, discutibles y compartibles. Como tales, obedecen a su vez a posiciones epistemológicas, identificables, ingenuas o elaboradas rigurosamente. Esa identificación se puede hacer a partir de los escritos que circulan en el interior de cada comunidad académica de especialistas; por lo que ya podría afirmarse, de entrada, que la enseñabilidad está cruzada por las lecturas que cada docente hace del saber que enseña, a partir de sus compromisos epistemológicos; sea o no pedagogo y didácta.

Podría ser, como sucede a menudo, que dentro de las miradas de tipo empiropositivista, los docentes se restringieran a la transmisión de los contenidos, siguiendo estrictamente la lógica disciplinar que presentan los textos, sin examinar cuáles son los compromisos epistemológicos que les subyacen. Para estos docentes, no es factible mirar los mismos textos desde otras posibilidades lógicas mucho más enriquecedoras en términos de la enseñanza. Esta enseñanza es la que se conoce como tradicional y en la cual la enseñabilidad es una propiedad parmenídea, en cuanto se deriva de la lógica disciplinar respecto de la cual no es realizable ninguna transformación. 
Para posibilitar dicha transformación habría que decir, que además de la lógica de los contenidos, habría que pensar en las lógicas de los aprendizajes. Tales lógicas empezaron a ser consideradas en la primera mitad del presente siglo (Taba, H., 1974). Luego, las nuevas elaboraciones epistemológicas indicaron la necesidad de revisar las concepciones que al respecto se manejaban en los textos didácticos (Hodson D., 1985). Esas nuevas elaboraciones abrieron también el debate en tomo a las relaciones entre las posiciones sobre la naturaleza de los saberes y aquellas acerca del aprendizaje de los mismos. D. Hodson (1988) anotó que era un error asumir esas relaciones como simples y directas. Además, J. G. Donald (1986), puntualizó que era menester diferenciar entre el contenido estructural de las disciplinas y las estructuras curriculares con las cuales se asiste a los alumnos, para que se aproximen críticamente a los saberes y desarrollen habilidades y destrezas en un saber disciplinar dado. Hoy, en consecuencia, esos compromisos empiropositivistas han sido objeto de revisión.

En este sentido, las elaboraciones deductivistas-constructivistas, que reconocen que los profesores han construido estructuras conceptuales, metodológicas, estéticas, actitudinales y axiológicas en el interior del saber en el cual ejercen pedagógica y didácticamente, han demostrado cómo ellos decodifican e interpretan ese saber, desde sus compromisos epistemológicos, incidiendo tales compromisos en las actividades de enseñanza que adelantan (Gallego Badillo, R. y Pérez Miranda, R., 1998). De ahí pues, que la enseñabilidad de un saber dado, no sea una propiedad intrínseca del mismo, sino una construcción que hace cada profesor o profesora, esto es, una atribución que depende del tipo de estructuras conceptuales, metodológicas, estéticas, actitudinales y axiológicas desde donde elaboran dicha atribución.

No se puede pasar por alto, en este ensayo, el hecho de que los empiropositivistas han separado lo conceptual de lo metodológico, de la misma manera como separaron la teoría de la práctica, consideradas como instancias diferentes del proceso cognoscitivo y reducida la última al seguimiento de un método único. Desde la penalización que han hecho de la subjetividad, parecen ser claras las razones por las cuales lo actitudinal y lo axiológico no han sido objeto de sus discursos epistemológicos; incluso, $\mathrm{K}$. Popper (1962), dijo que estos temas eran propios de la psicología y no de los análisis sobre la lógica de la investigación científica. Los constructivistas, por el contrario, son quienes han propuesto la necesidad de construir una estructura conceptual, metodológica, estética, actitudinal y axiológica para el examen de los saberes.

Además, si la enseñabilidad es una atribución que el profesor o la profesora elaboran a partir de sus compromisos epistemológicos, parece ser consecuente que él o ella han de responder por dicha construcción, de tal forma que no puedan eludir tal compromiso. Dígase, por tanto, que la lectura que hacen desde sí, le confiere al saber que enseñan una estructura disciplinar; requisito indispensable para poder elaborar la enseñabilidad.

De manera mucho más específica la interdisciplinariedad, la codisciplinariedad y la transdisciplinariedad de la mirada profesoral sobre un saber objeto de enseñanza, se enclava en el hecho de que la enseñabilidad y la enseñanza tienen su sentido cultural, social, político y económico, en la complejidad que es todo proyecto epistemológico, pedagógico y didáctico, el que a su vez, es congruente con el proyecto educativo institucional, del cual tiene necesariamente que hacer parte. Dígase que ninguna institución educativa es en sí un laboratorio científico, en el que lo disciplinar se halla reducido a sus propios presupuestos teórico experimentales (Fourez, G., 1997). 
En el mismo orden de ideas, la enseñabilidad está atravesada por la historia crítica del saben Un planteamiento hará el profesor o la profesora que desconocen esa historia o que sólo posea relatos de descubrimientos asombrosos hechos por hombres y mujeres geniales que nacieron programados y programadas genéticamente para cumplir esa misión. Otra será la enseñabilidad que elabore el profesor o la profesora que conozca una historia de teorías rivales (Popper, K., 1962), de paradigmas en competencia (Kuhn, T.S., 1977) o de programas de investigación competitivos (Lakatos, I., 1983), que en cada época han impulsado la creatividad en el interior de las comunidades académicas de especialistas; que sepa las razones por las cuales en cada época unas teorías, paradigmas o programas han sido de mayor aceptación que otras u otros.

La historia crítico-epistemológica de ese saber ha de mostrar cómo y de qué manera la estructura lógico disciplinar admitida, es un producto histórico; admisión en la que no sólo tuvo un peso específico la racionalidad interna de los miembros de la comunidad de especialistas, sino también la externa del proyecto político y económico que exigió a esa comunidad la demostración de la productividad de la teoría, del paradigma o del programa de investigación, para su apoyo social y financiero. Productividad en el amplio sentido del concepto. En otras condiciones la estructura lógico-disciplinar, a lo mejor podría haber sido otra, o la comunidad se habría decidido por otra.

Bajo el mismo convencimiento ya sostenido de que los saberes son comunitarios, hay que afirmar el hecho de que la enseñabilidad es también una construcción colectiva, en razón de que cada saber es enseñado por una comunidad de profesores que tienen sus revistas especializadas y se reúnen periódicamente en congresos, simposios, seminarios y coloquios. Incluso, en el interior de las mismas instituciones educativas discuten con cierta frecuencia sobre los diferentes enfoques con los cuales se enfrenta la enseñanza de ciertas temáticas y se consultan entre ellos. Así, las experiencias individuales se tornan comunitarias.

Téngase en cuenta, además, que el trabajo de enseñar es un acto público, sometido a la mirada crítica de los alumnos y alumnas, de toda la comunidad educativa, de la sociedad y sus diferentes y plurales organizaciones e instituciones. En estricto sentido no es una experiencia privada, por lo que, desde el punto de vista aristotélico, no puede ser un acto empírico supremo. Existe un discurso sobre la enseñabilidad, sea éste ingenuo o elaborado rigurosamente. Ese carácter público es el que concita a las discusiones y a las reelaboraciones, a la vez que a la responsabilidad de profesores y profesoras, que por lo dicho, no se restringen a cumplir solamente con el hecho de dictar las clases programadas a las horas indicadas.

La enseñabilidad elaborada se transmuta cuando se hacen aparecer los alumnos y las alumnas. Es decir, los fundamentos epistemológicos pasan a ser redefinidos desde los discursos pedagógicos y didácticos, desde los problemas del aprendizaje y la aprendibilidad, como de los del enseñar a leer y a escribir en el lenguaje o metalenguaje del saber objeto de enseñanza. Una será la enseñabilidad que construyen profesores y profesoras convencidos de que la cabeza de los alumnos y alumnas están vacías, que de aquello que da cuenta el saber que enseñan, ellos y ellas no tienen nada que decir al respecto. Otra será la enseñabilidad que organicen quienes trabajan, a partir de lo que los alumnos y alumnas ya saben, reconociendo esos saberes como posiciones pedagógica y didácticamente alternativas.

Destáquese, en lo que se ha venido sugiriendo, que en el caso de los investigadores en el problema de la enseñanza y el aprendizaje de las ciencias experimentales (Pérez 
Miranda, R. y Gallego Badillo, R., 1994), por lo menos, hay suficientes resultados para sostener que los presupuestos de una enseñabilidad fundada únicamente en las lógicas de las disciplinas, es académicamente insostenible. Son tales resultados los que hablan en favor de la constitución de una pedagogía y una didáctica de los saberes, como fundamento para puntualizar en una profesionalidad emergente.

La enseñabilidad elaborada especifica el proceso de enseñar, si éste se entiende como un concitar a los alumnos y alumnas para que construyan y reconstruyan las aprendibilidades individuales y colectivas, y se comprometan en sus actividades de aprendizaje. Son así cuatro factores los que interactúan de manera no lineal, haciendo que experimenten las transformaciones y evoluciones que la complejidad determine. Para repetirlo, la actividad de aprendizaje modifica la aprendibilidad, esta hace lo mismo con el enseñar $\mathrm{y}$, en consecuencia, con la enseñabilidad; transformación que se revierte sobre el enseñar y, por ende, en la aprendibilidad. Nótese, que de ser las cosas así, la relación de causalidad no puede ser la propia de los sistemas mecánicos simples (reduccionismo), porque, incluso, habría que tener en cuenta las interacciones enseñar-aprender; aprender-enseñabilidad; y enseñabilidad-aprender; todas ellas presentes en el acto pedagógico y didáctico.

Sin lugar a dudas, esa enseñabilidad se halla afectada igualmente por el grado y nivel de escolaridad en que se encuentren alumnos y alumnas, sino desde una aproximación racional y ponderada de ellos y ellas al saber objeto de enseñanza. Una cosa es llevar el saber a los alumnos y alumnas y otra bien distinta acompañarlos en su aproximación a dichos saberes. En esto desempeña un papel decisivo la estimación rigurosa de los saberes previos con los cuales ingresan alumnos y alumnas al proceso. De hecho, en el planteamiento de la enseñabilidad entre deductivistas-constructivistas, se hace necesario conocer a ciencia cierta esos saberes previos, ya que, de otra manera se actuaría pedagógica y didácticamente como si se fuera transmisionista.

La enseñabilidad se ve también, influenciada por las actitudes que el profesor o la profesora poseen en relación con el saber que enseñan y con lo pedagógico y lo didáctico de ese saber; es decir, en cuanto a esto último, con la actitud que ponen de manifiesto en lo relacionado con su profesión de enseñantes y, en consecuencia, con su profesionalidad y profesionalismo: compromisos y pertenencia a la comunidad académica de educadores.

Esa actitud es también construida históricamente desde tradiciones culturales y sociales, que tienen que ver con el proyecto político y económico en el interior del cual ser profesor, maestro, educador o docente tienen connotaciones de reconocimiento y validez, como ocupación intelectual y práctica. Ello obedece, sin lugar a dudas, al papel que el saber y la producción de saber tienen dentro de la historia de la constitución de una comunidad y sociedad dadas, para las cuales el orden del mundo y de la actuación en ese mundo, pueden obedecer o no al criterio de verdades absolutas, dadas de una vez y para siempre.

Traer a cuento los saberes pedagógicos y didácticos, significa conocer los aportes de la psicología de la cognición y los de la del desarrollo; los aportes de los lingüistas; los de los sociólogos y filósofos de la educación, como también la historia y la epistemología críticas de tales saberes. En el mismo orden de ideas, conocer los resultados obtenidos por los investigadores que se han ocupado y se ocupan de los problemas de la enseñanza y del aprendizaje del saber objeto de enseñabilidad, con el fin de conocer qué respuestas admisibles se han obtenido en otros lugares y bajo otras circunstancias y si son o no apropiadas y apropiables para la situación presente. 
De nuevo, subráyese que los problemas pedagógicos y didácticos desde las interacciones complejas y no lineales entre enseñabilidad, enseñar, aprendibilidad y aprender, son reales y que no son problemas psicológicos, ni sociológicos, ni filosóficos, en sentido estricto. Los pedagogos y didactas no son psicólogos, ni psicoterapeutas. La formulación de tales problemas pedagógicos y didácticos se comenzó a reconocer, a partir del momento en que los trabajos de J. Piaget, D. Ausubel y los teóricos del aprendizaje significativo y del aprendizaje como cambio, delimitaron con precisión conceptual, metodológica, estética, actitudinal y axiológicamente los objetos de saber y de investigación característicos de lo pedagógico y de lo didáctico.

Finalmente, hay que decir que la enseñabilidad se construye, además, bajo la perspectiva de las lógicas de las intencionalidades curriculares, que son también una construcción y praxis de las comunidades, que influyen (sin tergiversaciones) en las razones por las cuales un saber en especial, desde los fundamentos epistemológicos, pedagógicos y didácticos del currículo, hace parte integral del plan de estudios de una institución educativa dada. Estas son razones que van mucho más allá del afirmar simplemente que ese saber es importante, puesto que hay que dar explicaciones cognoscitivas, culturales, sociales, políticas y económicas en la perspectiva de la integralidad curricular

\section{Educar}

Es posibilitar que el educando despliegue todas las cualidades cognoscitivas de construcción conceptual, metodológica, estética, actitudinal y axiológica, de que es capaz. Hacer que crezca intelectual, social y éticamente. Esto lleva a hablar de la educación como la acción de educar en una óptica diferente, por lo que habría que distinguir entre una educación "natural" y otra "artificial", siendo esta última la de las instituciones educativas, direccionadas por concepciones epistemológicas, teorías pedagógicas, didácticas y curriculares, las cuales adquieren sentido en el seno de proyectos culturales, sociales, políticos y económicos.

La llamada aquí educación "natural", es un proceso que emerge de las distintas interacciones en las que, desde antes de su nacimiento, se encuentra inmersa la persona: usos, costumbres, creencias, suposiciones, mitos, ritos, normas e instituciones. Todas ellas expresadas concretamente a través de relaciones de sentido, en las que la construcción del lenguaje no es una simple imitación, sino una elaboración y permanente reelaboración de significados, formas de significar y de actuar; que no son otra cosa que la introducción paulatina a ese ordenamiento plural y multiverso que es la sociedad.

En gracia de discusión, admítase que la educación "natural" se sucede en el interior del llamado saber común, popular o cotidiano; que es también una clase de ordenamiento del mundo y de la vida y, por consiguiente, se constituye en el substrato a partir del cual cada persona, desde su nacimiento, inicia la elaboración de su orden interior y de su proyecto ético de vida. A partir de y en el seno del saber común, cada quien crea su propio horizonte de sentido, dentro de la necesaria y reclamada pertenencia comunitaria.

La categoría de orden es la requerida para fundar el análisis en tomo al problema de la educación y del educar; con la convicción de que proponer un orden único, es un ejercicio que va en contra de la misma naturaleza humana; de ahí la necesidad de sustentar en todo tiempo y lugar un orden plural y multiverso. La existencia del orden es la que dispara la inaplazable actividad de elaborar un ordenamiento interior que posibilite el "encajamiento" de cada quien con los demás. La pluralidad y multidiversidad son las que enriquecen esa construcción del orden interior y hacen factible la transformación no lineal 
de la sociedad. Educarse, es así, elaborar, desde sí, con los otros y en el seno de los otros, las condiciones para "encajar", pertenecer y jugar dentro de reglas respetadas por todos.

Educarse es, entonces, una decisión que toma cada sujeto, en cuanto a que decide por sí mismo pertenecer a ese orden cultural, social, político y económico. Una decisión, que por tal naturaleza es crítica y que no es, en todo tiempo y lugar un sometimiento alienable y alienante. La pertenencia jamás puede ser una obligación impuesta desde afuera.

La educación institucional obra en la misma dirección, en el interior, como ya se manifestó, de proyectos culturales, sociales, políticos y económicos que parten de la naturalidad señalada y en contra de ella, con miras a hacer que todos se identifiquen críticamente con el proyecto. Las instituciones educativas constituyen el nicho de los saberes académicos, comenzando por la lectura y la escritura. Esos saberes académicos son también ordenamientos, con sus metalenguajes, sus reglas, normas y ritos. Instauran además, sentidos del mundo y de la vida, distintos de los propios del saber común y cotidiano, en el seno del cual, procede la llamada aquí, educación natural. De esta manera, el orden académico choca con ese ordenamiento cotidiano, cuando la institución educativa no asume una especie de clausura con el entorno.

El problema central es que, de una manera u otra, en mayor o menor grado, todos los alumnos y alumnas proceden de ese saber común o cotidiano. Es el orden cultural y social que él constituye, el que suministra, como ya se dijo, el piso a partir del cual cada persona comienza a elaborar sus estructuras conceptuales, metodológicas, estéticas, actitudinales y axiológicas. Como es de esperarse, estas estructuras son diferentes de las propias de los saberes académicos. Esta diferencia es la que da origen a choques y polémicas, que obligan a que la enseñanza y el aprendizaje, la enseñabilidad y la aprendibilidad se lleven a cabo en un ambiente de negociación.

Por otro lado, los ordenamientos que instauran los saberes académicos tienen, en primer lugar, como referente el orden propio del saber común y cotidiano, del cual históricamente se han desprendido. En segundo lugar, que la existencia humana de cada quien tiene como sentido último el poder vivir con los otros y en el seno de los otros, por lo que el educarse en esos saberes académicos ha de tener como horizonte de sentido ese vivir; tal horizonte de sentido es el que incide en la modificación del saber común y cotidiano, haciendo que la cultura popular evolucione no linealmente.

Es en este contexto teórico, en el que cabe la idea de que las matemáticas, las ciencias, las tecnologías y todos los otros saberes académicos, que tienen su nido en la escuela, educan y contribuyen a una educación de otro tipo de las personas. Se comprende entonces cómo enseñar y aprender se codefinen con educar y educarse, a la vez que con la aprendibilidad y la enseñabilidad, conformando un triángulo de interacciones que hace que no puedan ser explicitados los unos sin los otros, pues de otra manera el discurso quedaría incompleto. Así, enseñar matemáticas, por ejemplo, es crear un ambiente para que el otro se introduzca en el orden que esta disciplina instaura, para construir una determinada mirada sobre el mundo; que aprender matemáticas es decidir desde sí, cómo y en qué momento encajar en ese ordenamiento; algo que no puede ser explicitado sino en términos de educar y educarse en matemática, desde su enseñabilidad y aprendibilidad.

Atendiendo a las interdisciplinariedades, codisciplinariedades y transdisciplinariedades, que hablan cómo y de qué manera históricamente todos los saberes académicos de una u 
otra manera, remota o actual están relacionados unos con otros, en sus apoyos conceptuales, metodológicos, estéticos, actitudinales y axiológicos específicos, es lo que permite sustentar que todos los saberes académicos, de manera mancomunada, educan y contribuyen a la educación de los escolares y de quienes han sido escolarizados.

Este enfoque, es el que refuerza la idea ya enunciada de la necesidad de que cada institución educativa sea un colectivo, una comunidad educativa. Es más, es ella la que en el concepto de educar, permite que se encuentren los profesionales de la educación.

\section{La educabilidad}

En principio y recordando viejos puntos de vista que tuvieron dominancia en épocas pretéritas, esta categoría corre el riesgo de ser conceptualizada en términos de plasticidad, de cómo el educando se deja moldear a voluntad y arbitrariedad del educador o educadora, bajo la justificación de que él o ella lo que buscan, en definitiva, es el bien del educando 0 de la educanda. Los estudiantes son asimilados, así sea metafóricamente, pero determinante de praxis educativa, a la idea de que son una masa informe o un bloque de mármol sobre el cual el educador o la educadora esculpen lo que quieren. Esta posición próxima a la de la creencia de que los estudiantes llegan con una mente vacía al proceso, carecen de estructuras conceptuales, metodológicas, estéticas, actitudinales y axiológicas. No. No es por ahí que hay que plantear el problema de la educabilidad, ya que niega todo el discurso actual acerca de la persona que son, por principio, el alumno y la alumna.

La educabilidad no puede dejar de lado las lógicas de las intencionalidades curriculares en la dirección incuestionable de que todo educando y toda educanda han de, finalmente, incorporarse críticamente al proyecto cultural, social, político y económico y a sus procesos de producción de bienes y servicios, con miras a sostener financieramente su proyecto ético de vida.

Regresando a la categoría de orden, en el contexto del reconocimiento a la pluralidad y multidiversidad, son todos los factores mínimos anteriores los que codeterminan ese orden y el ordenamiento epistemológico, pedagógico, didáctico y curricular, en el interior del cual la educabilidad se construye y adquiere su praxis real. Formularla es un ejercicio profesional en el cual hay que cruzar de manera compleja dichos factores. En principio habría que pensar en la intencionalidad de los educadores y educadoras, que por delegación cultural, han de introducir a los educandos en un orden dado; algo que ha de entenderse como una propuesta objeto de negociación.

Por otro lado, reconocer que educandos y educandas, si bien tienen la necesidad de encajar y de pertenecer a ese orden plural y multiverso, quieren hacerlo y lo hacen desde sus propias perspectivas, es decir, a partir del orden interior, conceptual, metodológico, estético, actitudinal y axiológico que ellos van elaborando y reelaborando, incluso, por fuera de las oportunidades que la sociedad y la institución educativa les brinda. En otras palabras, para poder encajar y pertenecer, ellos y ellas requieren primero arreglarse consigo mismos. Nadie puede ser obligado desde la exterioridad a someterse, ya que este someterse no genera compromisos y responsabilidades internas, como se ha sostenido.

Es esta la razón, para repetirla, por la que la educabilidad lleva implícito el reconocimiento del otro y que el educar, que se desprende de esa concepción de educabilidad, se traduzca en un acompañamiento del educando y de la educanda, para 
que ingrese desde sí y por sí mismo o misma, en el orden que se le ofrece como posibilidad de realización de su proyecto ético de vida. De manera consecuente, es darle la oportunidad para que construya dicho proyecto; intencionalidad para la cual los saberes académicos de la institución educativa han de ser formulados en su enseñabilidad requerida, en el orden de sus interdisciplinariedades, codisciplinariedades y transdisciplinariedades.

Sin lugar a dudas, en la construcción y perfeccionamiento de los proyectos éticos de vida, no inciden solamente las instituciones educativas y los profesores y profesoras. Intervienen construcciones históricas, culturales, sociales, políticas y económicas que tienen que ver con elaboraciones acerca del sentido de la vida individual y colectiva; de aquéllo que vale la pena ser dentro de ese ordenamiento; de las valoraciones que se dan a ese ser y pertenecer a la sociedad; y las estimaciones que se le dan a ciertas actuaciones, por encima de otras.

Al respecto, cabe anotar que tales condiciones inciden en la delimitación cognoscitiva de aquello que merece ser pensado y repensado, aquéllo que ha de ser objeto de reconstrucciones y construcciones de nuevos significados, formas de significar y de actuar. De esta forma, estimular, canalizar y apoyar la actividad cognoscitiva en una zona de interés para la supervivencia de la comunidad.

Obsérvese entonces cómo la educabilidad, en primer lugar, es una atribución que se dan a sí mismos, tanto el educando como la educanda, en la medida en que son ellos quienes optan por educarse en una dirección u otra. Pero es también una atribución que emerge de las interacciones colectivas, por cuanto ese educarse se da en el seno de los otros, a partir de los otros y con los otros, si se tiene en cuenta lo axiológico, la atribución de valor y, por tanto, el problema de lo ético que es eminentemente comunitario.

Lo colectivo, en el orden de las instituciones educativas, de la educabilidad significa también una elaboración en la cual inciden profesores, profesoras (que también poseen un discurso sobre la educabilidad) y la comunidad educativa en general, en cuanto a que configuran espacios para darle sentido a eso de ser educable. De hecho, es cada quien el que se educa y se hace desde sí educable, no como sometimiento, sino como una autodeterminación.

\section{A manera de conclusión}

El interrogante indaga por la construcción de un discurso en el cual se interrelacionen la aprendibilidad, la enseñabilidad y la educabilidad teniendo en cuenta que esa interrelación no puede dejar de lado los conceptos de aprendizaje, de enseñanza, de educar y de educarse. Acerca de los primeros, se ha hecho una propuesta. Faltaría mostrar cómo la educabilidad, el educar y el educarse se integran a los anteriores. Dígase, dentro de la teoría de complejidad y de la aproximación a la ontología de Heráclito, a partir de las cuales se ha planteado la discusión, que ninguno de estos conceptos tiene privilegios sobre los otros, ya que configuran una estructuración en la cual todos se codefinen, son inseparables y, por tanto, no pueden ser planteados y analizados desde la lógica cartesiana y mecanicista.

Si la educabilidad es una construcción que cada educando y educanda elaboran desde los presupuestos de sus proyectos éticos de vida, de forma que deciden educarse en términos de pertenencia crítica a unos ordenamientos, esa decisión obedece a una elaboración de sentido que procede por reconstrucción y construcción de nuevos 
significados, formas de significar y de actuar, vía un aprendizaje total. Educarse es así compartir ordenamientos en relación con tales significados y los sentidos que ellos direccionan actuacionalmente, con los otros y en el seno de los otros.

Esa atribución de educabilidad y de educarse en la pluri y multidiversidad que instauran los ordenamientos de la cotidianidad y de los saberes académicos, en principio, ligados a ella, responde a la necesidad de encajar, algo que no puede ser adelantado sino dentro de un proyecto ético de vida, a partir del cual cada quien Opta por educarse, con miras a que ese proyecto le permita ser lo que aspira a ser, en el espacio en el cual ese ser lo que se quiere, se mueve en el terreno de la negociación con los otros.

Dado que el ordenamiento se fundamenta en saberes, académicos y no académicos, entonces, la educabilidad y el educarse precisan, necesariamente de una atribución previa a esos saberes de la aprendibilidad de los mismos, de cómo han de ser aprendidos y qué se requiere para que ese aprendizaje sea significativo, en términos del proyecto ético de vida.

La enseñabilidad y la enseñanza han de inscribirse en esta complejidad; la cual hace que no existan relaciones directas y de relación causa-efecto simple, entre educar, enseñar y aprender; como tampoco, entre aprendibilidad, enseñabilidad y educabilidad. Es este el problema que inauguran las reflexiones que aquí se han hecho.

\section{Bibliografía}

AUSUBEL, D., NOVAK, J.D. y HANESIAN, H. 1983. Psicología educativa. Un punto de vista cognoscitivo. Segunda Edición, México, Editorial Trillas.

BRUNER, J. 1991. Actos de significado. Más allá de la revolución cognitiva. Madrid, Alianza Editorial.

1988. Desarrollo cognitivo y educación. Madrid, Ediciones Morata.

CARRASCOSA ALLIS, J GIL PÉREZ, D. 1985. "Science Learning as conceptual and methological change". Eur. J. Sci. Educ., 7 (3). 231-253.

DONALD, J. G. 1986. "Knowledge and te University Curriculum." Higher Education, 15, 267-282.

FOUREZ, G. 1997. Alfabetización científica y tecnológica acerca de la finalidad de la enseñanza de las ciencias. Buenos Aires, Ediciones Colihue S.R.L.

FURIO MAS, C. J. 1996. "Las concepciones alternativas del alumnado en ciencias: dos décadas de investigación. Resultados y tendencias". Alambique. Didáctica de la Ciencias Experimentales, No.7, 7-17.

GALLEGO BADILLO, R., PÉREZ MIRANDA, R. y TORRES DE GALLEGO, L. N. 1997.

"El concepto de aprendizaje total. Una aproximación teórica". Estudios en Pedagogía y Didáctica. Vol. 2, No. 1,4-13. 
GALLEGO BADILLO, R. y PÉREZ MIRANDA, R. 1997. La enseñanza de las ciencias experimentales. Santafé de Bogotá, Cooperativa Editorial Magisterio.

1994. Representaciones y conceptos científicos. Un programa de investigación. Santafé de Bogotá, Universidad Pedagógica Nacional, Departamento de Química.

GALLEGO BADILLO, R. 1991. "El programa de química orgánica en la formación de Licenciados en el Departamento de Química de la Universidad Pedagógica Nacional y el tipo de docencia que determina". (Tesis de Maestría). Santafé de Bogotá, Universidad Pedagógica Nacional, Facultad de Educación.

GENE, A. 1991. "Cambio conceptual y metodológico en la enseñanza y el aprendizaje de la evolución de los seres vivos. Un ejemplo concreto". Enseñanza de las Ciencias, 9(1). 26-27.

GUTZWILLER, M. C. 1992. “El caos cuántico”. Investigación y Ciencia, N0186, 14-20.

HAYLES, N. K. 1993. La evolución del caos. Barcelona, Editorial Gedisa.

HODSON, D. 1988. "Toward a phulosofically more valid science curriculum". Science Education 72 (1), 19-40.

1985. "Phylosophy of sciencie an sciencie education". Studies in Science Education. 12 (1), 25-27.

KUHN, T. S. 1972. La estructura de las revoluciones científicas. México. Fondo de Cultura Económica.

LAKATOS, I. 1983. La metodología de los programas de investigación científica. Madrid, Alianza Editorial.

MOREIRA, M. A. 1990. Opesquisa en ensino. O Ve Espistemológico de Gowin. Sao Paulo, Editorial Universitaria.

MORIN, E. 1996. Introducción al pensamiento complejo. Barcelona, Editorial Gedisa.

NOVAK, J. D. y GOWIIN, D. 1988. Aprendiendo a aprender Barcelona, Martínez Roca Editores.

PAGELS, H. R. 1991. Los sueños de la razón. Barcelona, Editorial Gedisa.

PÉREZ MIRANDA, R. y GALLEGO BADILLO, R. 1995. Corrientes constructivistas. Santafé de Bogotá, Cooperativa Editorial Magisterio,

POPPER, K. 1962. La lógica de la investigación científica. Madrid, Ediciones Tecnos.

POSNER, G. et al. 1982. "Acomodation of a scientific conception: Toward a theory of conceptual change". Science Education, 66 (2); 211-227. 
POZO, J. I. 1996. "Las ideas del alumnado sobre la ciencia: de dónde vienen, adónde van... y mientras tanto qué hacemos con ellas". Alambique, didáctica de las ciencias experimentales, No.7, 18-26.

SKINNER, B. F. 1986. Sobre el conductismo. Barcelona, Ediciones Orbis.

TABA, H. 1974. Elaboraciones del currículo. Buenos Aires, Troquel Editores. 